\title{
Women Engineers-Past, Present and Future Scenario
}

\author{
Savita Yadav \\ Netaji Subhash Institute of Technology \\ Sector-3, Dwarka, New Delhi, India \\ savitaydv@yahoo.com
}

\begin{abstract}
In modern times when we talk about the achievements and contributions in various fields made by men and women in the same breath, Is there really a need to discuss about the topic in concern "Women in Engineering". Indeed as they say "there is no smoke without fire", many research studies conducted by independent/funded organizations reveal startling facts regarding standing of women in male dominated arenas. Engineering is one such prominent field which has long been considered as a tough guys work. Owing to preconceived notions, lack of support, dismal encouragement and biasness, women often hesitate in taking up engineering as a career option. This paper summarizes the work done by pioneering studies existing in literature which have made significant say in the present condition of women in this field, the reasons which are holding back this bunch of talent, the hues and cries, and the possibility of further steps needed to mitigate this trend of downfall in the number of women engineers, thereby targeting engineering education in 2025 with no disparity between men and women.
\end{abstract}

\section{Savita Yadav}

Netaji Subhash Institute of Technology

Sector-3, Dwarka, New Delhi, India

savitaydv@yahoo.com

\section{Background}

According to an article published in New York Times in 2015, at Apple 20 percent of technology jobs are held by women and at Google, only 17 percent. This underrepresentation is disturbing from several perspectives: nearly half the prospective talent for the technical workforce is missing from action. Women have made remarkable progress in education and the workplace during the past 50 years. Especially in male dominated fields such as business, law, and medicine, women have made striking gains. In science, technology, engineering, and mathematics, however women's advancement has been slower, especially in engineering. In sociological terms, various studies suggest different ways in which it clearly comes out that engineering is indeed 'gendered'. Several studies show that professional engineering continues to be seen as masculine, women in engineering are seen as exceptions, who have to continuously prove their mettle in order to sustain their credibility in the long run. Despite some resolute attention and resources devoted to conscription and withholding of women in engineering over the last couple of decades, they are still dolefully underrepresented in engineering. The stereotype that links masculinity to technology is ,unfortunately, still prevalent and difficult to overcome. We need to dig deeper to the core of this issue, find the reasons for this enormous inconsistency, its implications to the academic world and perhaps for the society in general.

\section{Reasons: Facing the truth}

Before we really begin to understand the scope of steps necessary to be taken in this regard, it is extremely important to know the main reasons behind this difference in representation of women vis-a-vis men in the field of engineering. As per the report published by The American Association of University Women (AAUW),2008 the factors contributing to the disparity between number of men and women in this field are organized into three areas: social and environmental factors shaping girls achievements and interest in math and science; the college environment; and the continuing importance of bias, often operating at an unconscious level, as major hurdles to women's success in engineering. In developing nations like India, society 
plays an important role in choosing one's career. Societal pressure and nearby environment can be most easily witnessed at the lower and middle class levels. A girl is often looked down as mere burden, thereby little or no interest is given to her academic inclinations, most of the time incurring expenses on her basic education is seen as a waste of money. If she is sent to a formal school, they are recurrently demoralized by the callous attitude shown to them by fellow male classmates, who have negative stereotypes about girls' abilities. They often feel shy in raising queries about the concept not well understood, as a consequence of this they loose appetite to learn and develop low self esteem. Lack of interest or misperceptions on the part of students are not the responsibility or domain of any one institution or system. They are impelled by a social fabric that pervades our society, represented not only within our educational systems but also in homes, within families, which ,by and large, stereotypes engineering and scientific fields as "geeky" and particularly inappropriate for girls and women.

One of the largest gender differences in cognitive abilities is found in the area of spatial skills, with boys and men consistently outperforming girls and women. The striking disparity between the numbers of men and women in engineering domain has often been considered as evidence of biologically driven gender differences in abilities and interests. It is often formulated that men naturally excel in mathematically demanding disciplines, whereas women naturally excel in fields using language skills. In the light of this, it is to be examined as to what challenges we are facing? Then subsequently we need to consider and devise strategic solutions to counteract this major predicament.

\section{Challenges in store}

Despite some concerted attention and resources devoted to recruitment and retention of women in engineering over the last couple of decades, they are still woefully underrepresented in this field. The challenges which needs to be tackled are:

A. The technological/social dichotomy-This draws on the conventional gendering of a dualism between 'the technical' realm and 'the social', by which men are so readily associated (symbolically) with technology and women with people. So we need to ask whether to be technical is not to be social and vice versa? The kind of image perceived to be of an engineer really fits into what real engineers actually are. Even today, people cannot comprehend a woman engineer doing the work as efficiently as her male counterpart. While working in a cool AC room in a IT sector is perfectly acceptable for a woman, most people would raise an eyebrow, if a woman were to roll up her sleeves of shirt and work on a machine or slide under a truck to mend it!! These stereotypes at first place get many women thinking about taking up engineering as a career option or not.
B. Lack of Role Models/Mentor-Technical education is definitely more expensive, than other degrees. In India, there is still a large percentage of population, who are of the view that heavy investment in a girl's education as a wasteful expenditure. This lack of solid financial support is one more reason why, girls are not able to join engineering degrees. Even if they do join, during the formative years in engineering colleges, girls often find a lacuna in the sense that they can hardly find some mentor in the terms of women faculty in engineering. There is also a huge underrepresentation of women in teaching engineering subjects. Faculty mentorship has been known to be very important. Since, we are still in the transition stage, Indian universities and engineering colleges do not have many women in positions of deans, principals, or directors. There is still a bias in the minds of the administrators, about women heading technical institutions. This often adds to their dilemma surmounted by the fact, they can also not relate or identify or look up to a women engineer in the vicinity.

C. Organizational Climate- The challenges and pathetic experiences at work exercises a strong influence on determining these women's perceptions of subjective career success. Prominent among such factors was the experience of incivility at work that was reflected in the extent to which the supervisors, senior managers and co- workers generally treated women in a condescending, demeaning or insolent manner and specifically undermined their efforts at being successful at work. Quintessentially, of the different types of workplace barriers that are prevalent, the two that most negatively influenced women's contentment levels were work-role ambiguity and a work environment that consistently undermined and belittled them. Women engineers who handled unwarranted and contradictory work-role demands, and worked in environments where women were treated in a lofty manner, experienced considerable work and non-work conflict.

D. Work/Life Balance- A survey of male and female engineers revealed that women who experienced high levels of work-family conflict were less likely to be retained by their employers compared to their male coworkers (National Science Foundation, $S$ \& E Indicators, 2002). Predictably, women with childcare responsibilities experienced greater interference between their work and parental (non-work) roles than those without such responsibilities. Work and non-work roles are thoroughly and inextricably associated in most people's lives. What happens in one's job and career affects one's individual and family life. For example, a good (or a bad) day at work may affect one's frame of mind when interacting with 
family and friends after work. The things that happen in one's personal life - the friendships and family responsibilities-also affect one's job or career. For example, a spouse's (or partner's) career may prevent one from accepting a relocation offer. Given the multiple, competing and often simultaneous demands and pressures that employees face, friction between their work and non-work roles is inevitable.

E. Psychological Factors-It is often reported in many psychological surveys, women seem to assimilate negative perception of their abilities. There may be many social reasons behind this development of their mindset, especially in India. The major challenge which needs to be handled is how to retain their confidence and self-efficacy. Women feel that their organizations do not take them seriously, that they do not receive challenging opportunities and subsequently do not receive the pay or positions commensurate with their talents. This has tremendous amount of impact on the psychological well being of women engineers. Many quit their field jobs owing to the dearth of challenging opportunities and rewards. This has cascading effect on the other fellow women engineers working in same deplorable conditions. They feel let down and out.

\section{Action Plan-Steps to be enforced}

A. Nip in the bud-If we really need to work on improving the number of women in engineering, we have to start early at the grassroot levels and focus on the kind of education being imparted at the schools. Wendy Hawkins, executive director at the Intel Foundation, believes middle school is a critical decision making time for female students. Kids finally have the education to make their own class schedule choices, and exciting and engaging work appeals to them. Are enough foundation courses being taught at the school which clearly aims at understanding of the concept and building blocks of STEM(Science, Technology, Engineering , Maths).Work needs to be done to make arrangements for the training facilities of teachers, discuss their current work and answer queries about career opportunities. This learning they can take to their classrooms and provide relevant guidance that many students are seeking.

B. Busting the stereotypes and Prejudices-Society as a whole has to take into consideration that the negative stereotypes and prejudices against girls regarding STEM streams are society made and they are in dire need to be shed if mankind in general and female in particular, has to progress.
For the smooth and swift progression of society, these negative typification needs to be shelved as research by Campbell et al. 2002,suggests that the achievement in maths between girls and boys is nearly same. Similarly, Seymour and Hewitt,1997;Adelman 1998, also showed that women leaving the science and engineering majors in college have higher GPA's than do men who continue. It clearly precludes the prejudice against women and reflects that this gender difference is related to some other factor, but not with women's ability or aptitude. It might be the negative stereotype which is well entrenched into the social fabric at every level, resulting in the lack of interest in these fields by girls. Important members of the society including teachers and parents can encourage a growth mindset amongst girls by having trust in their intellectual abilities.In order to ensure a better and growth oriented society,rather than emphasizing the "innate sexual differences and steroeotypes,the system has to encourage and wholly support the women who aspire to innovate and establish themselves in STEM. They must be motivated to develop interest and achieve in the STEM by breaking the persisting taboos existing in the society about their abilities. Research findings suggest that girls who trust that their intellectual abilities can be improved with learning and experience do better in maths test and there are more chances of them to continue in engineering in future.

C. Behavioral changes of organization- It is high time that multi-national companies, organizations wake up to the need of the hour. Examination of data reveals that women often feel marginalized and excluded from significant role in their organizations. This marginalization was often accompanied by differences in salary, space, awards, resources, and response to offers between men and women. The gravest implication of this prejudice is that aspiring women engineers when encountering the newest obstacles in their career path, might find it useless to press on and continue to fight an uphill battle. If this continues, the deficit of women engineers will also mean a setback in terms of new ideas, talent, and in the long run, innovation.Similarly, Gill,2005 while looking at the role of women in academia and sciences emphasized that the academicians must design the science curricula in such a manner that it becomes "equally satisfying to men and women". If the organizations want to exploit maximum potential of the work force available and reap the rewards, it is time they need to bring about change in the way they treat their women employees, it is for them to ensure this by providing a welcoming and conducive environment wherein women can work and thrive. There is immense need to rework on the existing policies, work culture, to suit everybody's need. There is 
a need to strengthen the recruitment, support, and advance of women pursuing this career.

D. Paradigm Shift of views in the Society-Researches showed that negative stereotypes in the society about the girls abilities in STEM indeed lowers their performance and aspirations for them as their career option's. By changing in the learning environment from the very starting that they are equally able, it can improve their achievements in engineering. Research suggest that due to this cultural stereotypes girls often assess their mathematical abilities and skills lower in comparison to boys with similar mathematical achievements. In order for both the gender to achieve equally in STEM, parents and educationists should motivate and help girls to assess their abilities with more precision. Hence a cautious approach is required in which gender differences should not be emphasized as both the gender are more similar than they are different. As the expectations greatly influence the behavior and learning (Steele,1999), hence by getting away with differential expectations through deliberately motivating the women can be a great help.

\section{GIRLS IN ENGINEERING} ADVICE BY CANDY TORRES

It's not about ability but opportunity.

Follow your instind \& talk about your passion.

Find a leader who focuses on teambork.

Women's colleges can be a great ptace for

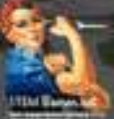

leadership training \& encouragement.

E. Providing role models/mentors- Mentoring is very often employed strategy for retention of women in engineering. It is often poorly practiced and its importance is underestimated. At its weakest, mentoring is viewed as a somewhat off hand strategy to provide helping hand to weaker and less confident students. But it is much more than that, one has to dig deeper. Once in college, women are somewhat more likely than men to doubt their ability to succeed in technical fields such as engineering. Lack of confidence further influences women's decision to persist this field or not in the long run. MentorNet,2002 suggests that mentoring appears to be a strategy that helps increase women's confidence in their abilities. According to Zachary,2000 mentoring is understood as a serious and powerful learning process, complete with the need to establish learning objectives, measures, and discipline to achieve results, its potential

can be realized.Clutterback,2001 contended,while supporting mentoring as essential part in transferring the knowledge between generations, that it assists in gaining the tactical knowledge of a specific field and develop an individual as a professional. Policymakers, program developers need to better understand how best to construct mentoring experiences that can be valuable and powerful in their transformation of individuals and organizations. With the widespread use of internet technologies and clever adaptation of technologysupported solutions, it is possible to enable electronic mentoring program linking students with professionals in industry in both scalable and cost-effective way. We also need to expose girls to the role models who describe their own experiences and challenges and how they overcame can also help students see their struggle as a normal part of the learning process rather than as a signal of low ability.

F. Training on the Job - Early days on the job can be baffling, there are initial hiccups, where one realizes 'how little engineering there is'. One realizes that there is a need of more rounded engineering knowledgerelated to business processes, work relationships and the like. It is often built slowly and iteratively. A fresh graduate has to figure out a way to swim across. Along the way, there are a number of critical milestones, decision making moments, realization that you are getting it right and that people are asking questions, getting positive feedback superiors and clients, running the project from start to finish. So acquiring engineering expertise goes hand-in-hand with gaining confidence. Women and men engineers face more or less same struggle in their initial years of career, both have to prove their worth. There should not be any gender dynamics deciding how easily one gains membership (or not) in engineering communities.

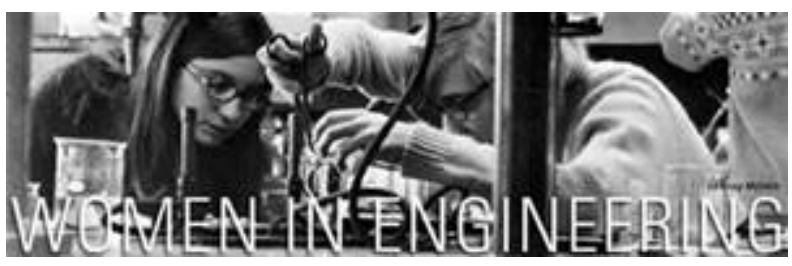

Fig. 2

G. Support networks and mutual support- It is clearly evident that women entering the field of engineering are typically in an even smaller minority. As a result of that they particularly discover appreciating and benefitting from the solidarity of other women engineers, either as immediate colleagues or through network of women engineers. There should be a sense of belongingness and acceptability for women in the field of engineering, which ultimately culminates into shared identities and pleasures and a membership in their 
workplace culture.And throughout early years on the job, women and men alike often seek out, and gain considerably from, solidarity with other junior engineers. So there is a need to facilitate networking and mutual support, encouraging a culture where asking questions is a norm.

\section{Conclusion}

Having discussed at length the present state of affairs, the cause of concerns, vital steps mandatory to initiate reforms at root levels, let's not conclude. Rather we should all embark on this journey collectively, it is for all of us to decide judiciously in whatever little way we can be of help in taking the number of women engineers from dismal to maximal. We have to strive ahead in technology with equal representation from both the genders as both men and women engineers are motivated by the same aspirations and challenges. It is not only about male and female progress, but we have to see the other perspective, where both these communities offer their best to the world, to the mankind in general.

\section{References}

AAUW (2008). Where the girls are: The facts about gender equity in education, by C. Corbett, C. Hill, \& A. St. Rose. Washington, DC: Author.

Adelman C. Women and Men of the Engineering Path:A Model for Analysis of Undergraduate Careers.U.S. Department of Education, The National Institute for Science Education;Washington,DC:1998.

Campbell P,Jolly E,Hoey L,Perlman L.Upping the Numbers:Using Research-Based Decision to Increase Diversity in the Quantitative Disciplines.2002 A report commissioned by the GE Fund.

Clutterbuck D.London:CIPD Publishing;2001.Everyone Needs a Mentor. Chartered Institute of Personnel and Development. Gill,Kathy."Women in Academia and the Sciences."About Inc.2005.13 April 2005 http://uspolitics.about.com/od/electionissues/a/women_science. htm.

MentorNet. 2000-01 MentorNet Evaluation Report. 2002. http://www.mentornet.net/Documents/About/Results/Evaluatio n/00-01/00.01.YearEnd.Eval.Report.appendices.pdf.
National Science Foundation.Science and Engineering Indicators 2002, Chapter 3:Science and Engineering WorkforceWomen and Minorities in S\&E.http://www.nsf.gov/sbe/srs/seind02/

Seymour E,Hewitt N. Talking About Leaving:Why Undergraduates Leave the Sciences .Westview Press;Boulder,CO:1997.

Steele C.Thin Ice:"Stereotype Threat" and Black College Students.Atlantic

Monthly.Aug,1999.1999.http://www.threatatlantic.com/issues/9 9aug/9908stereotype.htm.

Zachary L. The Mentor's Guide.Jossey-Bass Inc.;San Francisco,CA:2000. 